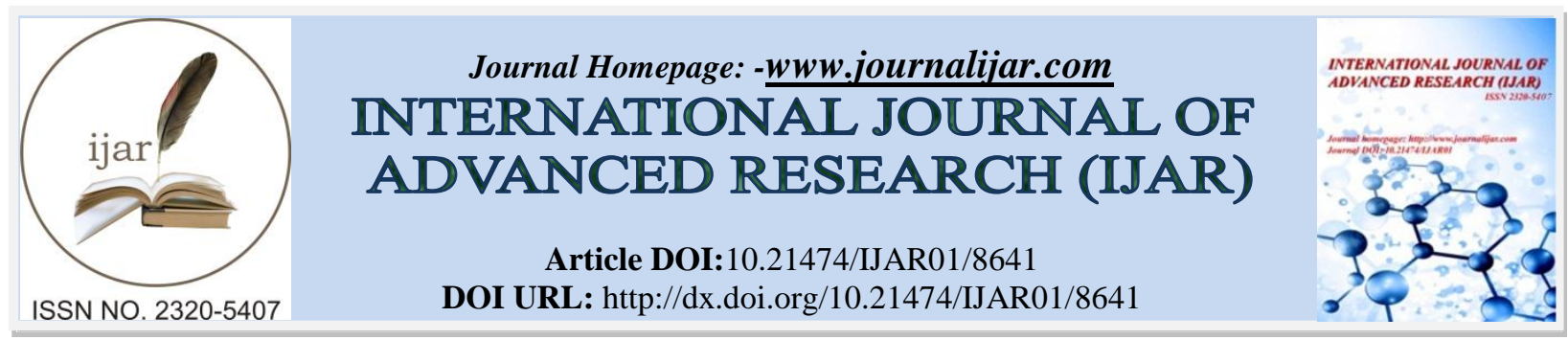

RESEARCH ARTICLE

\title{
A RETROSPECTIVE STUDY OF AUDITORY ANALYSIS IN NON INSULIN DEPENDENT DIABETIC PATIENTS.
}

Sivasubramanian $\mathbf{T}^{\mathbf{1}}$, Dhinakaran $\mathrm{N}^{\mathbf{2}}$ and Karthikeyan $\mathbf{B} \mathbf{M}^{\mathbf{3}}$.

1. Assistant Professor, Department of ENT, Madurai Medical College and Government Rajaji Hospital, Madurai.

2. Professor and HOD, Department of ENT, Madurai Medical College and Government Rajaji Hospital, Madurai.

3. Speech Therapist and Audiologist, Department of ENT, Government Rajaji Hospital, Madurai.

\section{Manuscript Info}

\section{Manuscript History}

Received: 08 January 2019

Final Accepted: 10 February 2019

Published: March 2019

Key words:-

Behaviour, determinant, factor, health, seeking.

\begin{abstract}
Diabetes mellitus (DM) comprises a group of common metabolic disorders that share a phenotype of hyperglycemia. Diabetes mellitus can be broadly classified as adult onset diabetes mellitus (type II) and juvenile onset diabetes mellitus (type I). The current study aimed to establish the relationship between age, duration, severity and complication of diabetes to the changes in hearing threshold and also to find out the prevalence of hearing impairment in diabetic population. The subjects included in the study were 100 diabetic patients (50 Males and 50 Females) in the age range of 30 to 60 years who served as experimental group and 100 healthy age and sex matched candidates served as control group. All the subjects had undergone pure tone audiometry evaluations and the hearing threshold at different frequencies was compared between both groups. The results showed that hearing threshold in experimental group was higher than the control group. Also, the comparison within the diabetic group on age and duration of diabetes mellitus and hearing threshold showed a significant difference with increased hearing impairment with increase in age and duration of diabetes mellitus. Hence the study concluded with direct correlation between diabetes and hearing impairment and the DM patients were advised to undergo periodic audiological evaluations and management.
\end{abstract}

Copy Right, IJAR, 2019,. All rights reserved.

\section{Introduction:-}

Diabetes mellitus is a chronic metabolic disorder which is classified as non - insulin- dependent diabetes mellitus or insulin dependent diabetes mellitus, which corresponds to the previous labels of adult onset diabetes mellitus (type II) and juvenile onset diabetes mellitus (type I). The incidence of diabetes mellitus is found to be around 7.1\%. NonInsulin dependent diabetes is more common in obese and older patients, with strong genetic predisposition. Fewer microvascular complications are seen such as hearing impairment and there is a higher risk of large vessel atherosclerosis, coronary disease and peripheral vascular disease.

The literature exhibits many contradictions concerning the correlation between hearing impairment and diabetic manifestations. The typical hearing loss described in diabetic population is progressive, bilateral sensorineural

Corresponding Author:-Sivasubramanian T.

Address:-Assistant Professor, Department of ENT, Madurai Medical College and Government

Rajaii Hospital, Madurai. 
deafness of gradual onset which affects predominantly the higher frequencies and older patients. There is a decrease in auditory acuity which is similar to that of presbyacusis but those affected show a hearing loss greater than could be expected at that age.

Huang et al (1990), in a study of 43 diabetic subjects compared with age and sex matched controls found statistically significant differences between the two groups for the average over 500, 1000 and $2000 \mathrm{~Hz}$ in addition to an increased incidence of recruitment, reduced speech discrimination scores and prolongation of the I - V interpeak latency on ABR testing and concluded with predominantly cochlear damage with high frequency hearing loss. Heinemann et al(1992), concluded that non-insulin dependent diabetic patients were not deafer than the control group and suggested that differing conclusions by other authors could be related to the different methods and criteria used. Abdullahi Isa et al (2012) also reported that mild sensori neural hearing loss is the main type of hearing impairment in diabetes and the duration of illness correlated significantly with the hearing impairment. In a study by Sheetal Krishnappa (2014), found that diabetes mellitus was associated with higher hearing loss compared to presbycusis and hearing threshold was to affect all frequencies, but significantly the higher frequencies in diabetics. Stephen semen yikawe et al (2017), in their study reported that as the duration of hyperglycemia increased, the hearing threshold among participants also increased.

\section{Objectives of the study:}

The objectives of the current study were to establish the relationship between age, duration, severity and complication of diabetes to the changes in hearing threshold and also to find out the prevalence of hearing impairment in diabetic population.

\section{Materials and Method:}

The present study is a hospital based prospective study of all consecutive adult diabetic patients aged between 30 years to 60 years, who have attended the endocrinology and ENT outpatient departments of Government Rajaji Hospital, Madurai from July 2018 to December 2018. In this study, Group I with 100 healthy subjects (50 Males and 50 Females) served as control group and experimental group (Group II) comprised of 100 subjects (50 Males and 50 Females) diagnosed as cases of NIDDM diabetes Mellitus without and with complications like peripheral neuropathy, diabetic retinopathy, hypertension, nephropathy, congestive cardiac failure/ ischemic heart diseases. All the subjects included in the study were subjected to through ENT examination to rule out any organic pathology in the external and middle ear and Audiological evaluation was done with MAICO MA 52 Pure Tone Audiometer. The audiological evaluation included both air conduction and bone conduction assessment at $250 \mathrm{~Hz}, 500 \mathrm{~Hz}, 1000 \mathrm{~Hz}$, $2000 \mathrm{~Hz}, 4000 \mathrm{~Hz}, 6000 \mathrm{~Hz}$ and $8000 \mathrm{~Hz}$. The results were recorded on audiogram sheets for all patients.

\section{Results and Discussion:}

A group comparison of audiological evaluation reports were made between control group and experimental group on the following variables: presence of hearing loss, relationship between age and average hearing threshold of both groups, duration of diabetes and hearing impairment within experimental group.

\section{Comparison of average hearing threshold between control group and experimental group:}

\begin{tabular}{|c|c|c|c|c|c|c|c|c|c|c|c|c|c|c|}
\hline \multirow[t]{2}{*}{ Group } & \multicolumn{14}{|c|}{ Average hearing threshold in different frequencies $(\mathrm{dB})$} \\
\hline & \multicolumn{2}{|c|}{$250 \mathrm{~Hz}$} & \multicolumn{2}{|c|}{$500 \mathrm{~Hz}$} & \multicolumn{2}{|c|}{$1000 \mathrm{~Hz}$} & \multicolumn{2}{|c|}{$2000 \mathrm{~Hz}$} & \multicolumn{2}{|c|}{$4000 \mathrm{~Hz}$} & \multicolumn{2}{|c|}{$6000 \mathrm{~Hz}$} & \multicolumn{2}{|c|}{$8000 \mathrm{~Hz}$} \\
\hline Exp.Group & $\mathrm{R}$ & $\mathrm{L}$ & $\mathrm{R}$ & $\mathrm{L}$ & $\mathrm{R}$ & $\mathrm{L}$ & $\mathrm{R}$ & $\mathrm{L}$ & $\mathrm{R}$ & $\mathrm{L}$ & $\mathrm{R}$ & $\mathrm{L}$ & $\mathrm{R}$ & $\mathrm{L}$ \\
\hline $\mathrm{BC}$ & 20 & 19 & 20 & 19 & 20 & 20 & 20 & 20 & 23 & 24 & & & & \\
\hline $\mathrm{AC}$ & 28 & 29 & 28 & 29 & 28 & 29 & 30 & 30 & 34 & 36 & 40 & 40 & 54 & 54 \\
\hline $\begin{array}{r}\text { Cont.Group } \\
\text { BC }\end{array}$ & 10 & 10 & 10 & 10 & 10 & 15 & 10 & 15 & 15 & 15 & & & & \\
\hline $\mathrm{AC}$ & 10 & 10 & 10 & 12 & 12 & 12 & 12 & 15 & 15 & 15 & 15 & 16 & 15 & 16 \\
\hline
\end{tabular}

$\mathrm{P}$ Value $=<$

Table 1:-Comparison of average hearing threshold in different frequencies between control group and experimental group 


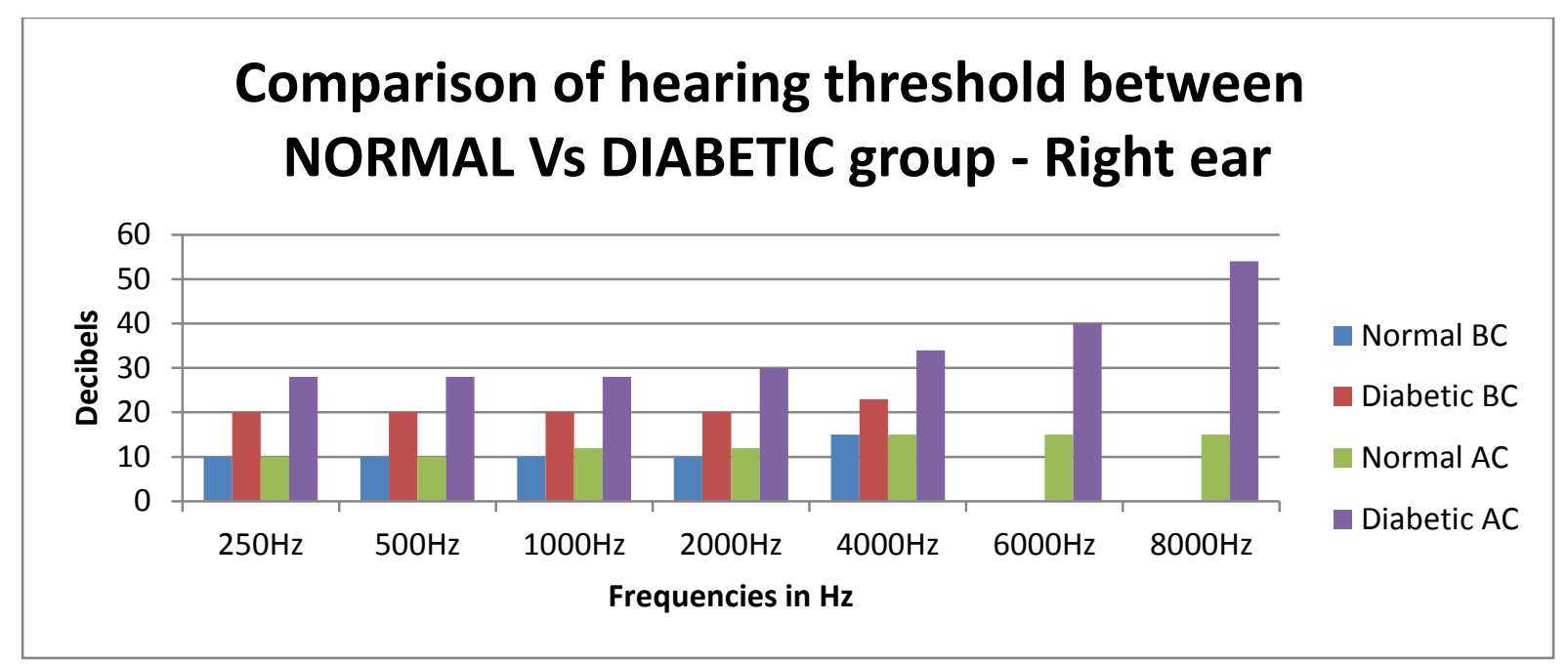

Graph 1:-Hearing threshold comparison of different frequencies between Normal and diabetic group in Right ear

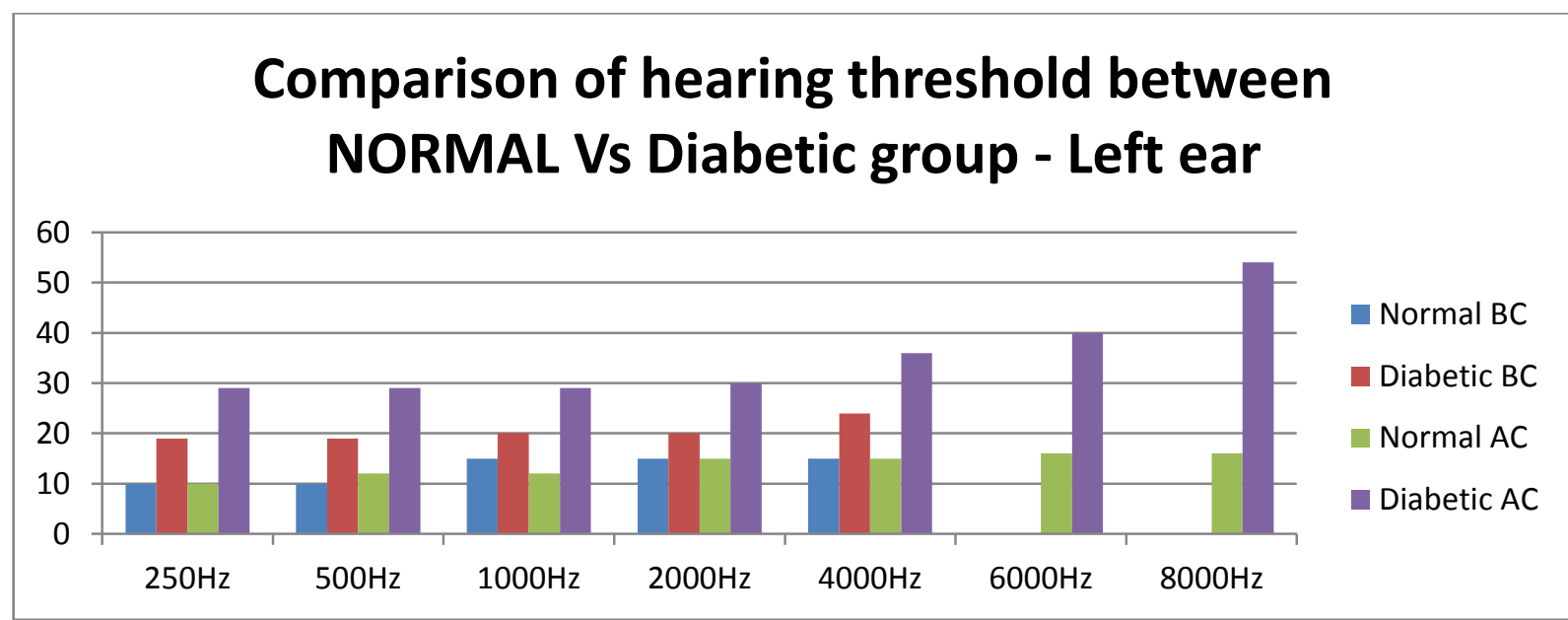

Graph 2:-Hearing threshold comparison of different frequencies between Normal and diabetic group in Left ear

From Table -1 and Graph $1 \& 2$, it can be clearly inferred that the mean frequency at each frequency of all experimental subjects were higher than the control subjects. Average threshold in different frequencies were highly significant. $\mathrm{P}$ value is $<0.01$ for both bone conduction and air conduction in both ears. An average of $40 \%$ diabetic group was affected in average thresholds and especially in higher frequencies in both ears.

2. Relationship between age and average hearing threshold in different frequencies among the experimental group:

\begin{tabular}{|c|c|c|c|c|c|c|c|c|c|c|c|c|c|c|}
\hline \multirow[t]{2}{*}{ AGE } & \multicolumn{14}{|c|}{ Average hearing threshold in different frequencies } \\
\hline & \multicolumn{2}{|c|}{$250 \mathrm{~Hz}$} & \multicolumn{2}{|c|}{$500 \mathrm{~Hz}$} & \multicolumn{2}{|c|}{$1000 \mathrm{~Hz}$} & \multicolumn{2}{|c|}{$2000 \mathrm{~Hz}$} & \multicolumn{2}{|c|}{$4000 \mathrm{~Hz}$} & \multicolumn{2}{|c|}{$6000 \mathrm{~Hz}$} & \multicolumn{2}{|c|}{$8000 \mathrm{~Hz}$} \\
\hline $30-40$ & $\mathrm{R}$ & $\mathrm{L}$ & $\mathrm{R}$ & $\bar{L}$ & $\mathrm{R}$ & $\mathrm{L}$ & $\mathrm{R}$ & $\mathrm{L}$ & $\mathrm{R}$ & $\mathrm{L}$ & $\mathrm{R}$ & $\mathrm{L}$ & $\mathrm{R}$ & $\mathrm{L}$ \\
\hline BC & 20 & 21 & 20 & 21 & 21 & 20 & 21 & 23 & 25 & 26 & & & & \\
\hline $\mathrm{AC}$ & 30 & 30 & 32 & 32 & 32 & 32 & 33 & 33 & 33 & 33 & 40 & 40 & 44 & 45 \\
\hline $41-50$ & & & & & & & & & & & & & & \\
\hline $\mathrm{BC}$ & 20 & 22 & 22 & 22 & 21 & 22 & 21 & 23 & 25 & 25 & & & & \\
\hline $\mathrm{AC}$ & 29 & 30 & 29 & 30 & 28 & 29 & 30 & 34 & 35 & 41 & 42 & 42 & 47 & 53 \\
\hline $\begin{array}{c}51-60 \\
\text { BC }\end{array}$ & 24 & 24 & 24 & 23 & 24 & 24 & 25 & 26 & 27 & 27 & & & & \\
\hline $\mathrm{AC}$ & 32 & 31 & 33 & 33 & 34 & 34 & 34 & 34 & 40 & 41 & 44 & 44 & 54 & 56 \\
\hline
\end{tabular}

Table 2:-Relationship between age and average hearing threshold in different frequencies among the diabetic group 


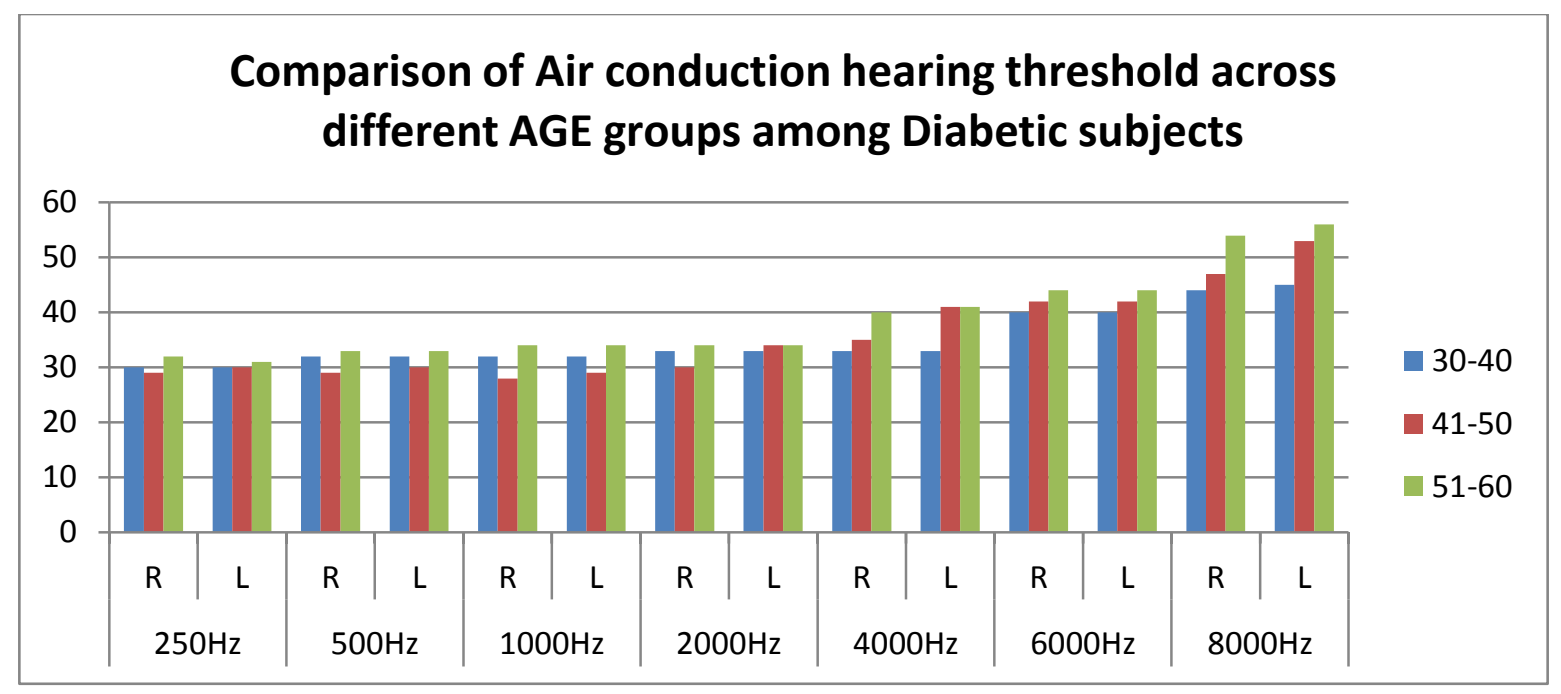

Graph 3:-Comparison of Air conduction hearing thresholds across different age groups among diabetic group

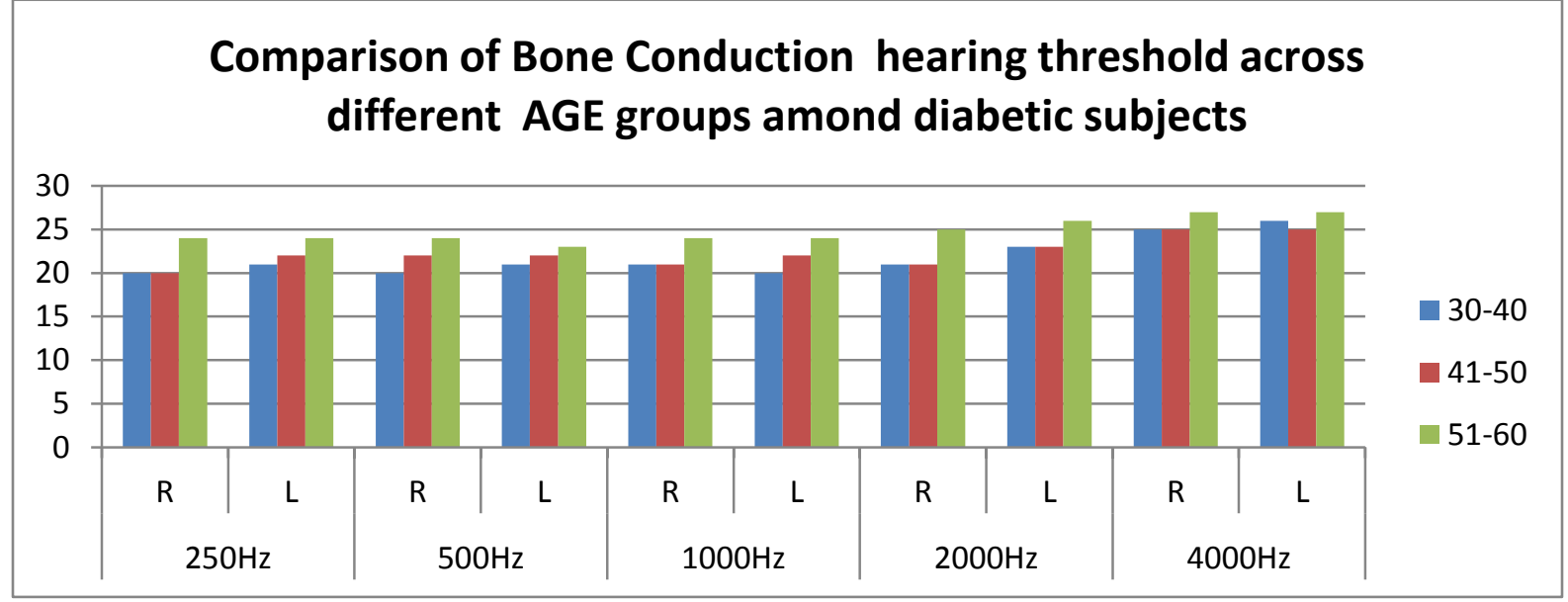

Graph 4:-Comparison of Bone conduction hearing thresholds across different age groups among diabetic group

From Table -2 and Graph $3 \& 4$, it can be easily predicted that with increase in age, the diabetic group found to have elevated thresholds and the high frequencies were affected in both ears. A positive relationship between age and hearing impairment among diabetics was reported by Ferrer et al (1991), Kutty et al (1998) and Sheetal krishnappa (2014). The results of the current study also support the previous reports with increase in hearing thresholds in diabetic group with increase in age.

3. Relationship between hearing thresholds and duration of Diabetes mellitus:

\begin{tabular}{|c|c|c|c|c|c|c|c|c|c|c|c|c|c|c|}
\hline \multirow{3}{*}{$\begin{array}{c}\text { Duration } \\
\text { of DM in } \\
\text { years }\end{array}$} & \multicolumn{14}{|c|}{ Average hearing threshold in different frequencies } \\
\hline & \multicolumn{2}{|c|}{$250 \mathrm{~Hz}$} & \multicolumn{2}{|c|}{$500 \mathrm{~Hz}$} & \multicolumn{2}{|c|}{$1000 \mathrm{~Hz}$} & \multicolumn{2}{|c|}{$2000 \mathrm{~Hz}$} & \multicolumn{2}{|c|}{$4000 \mathrm{~Hz}$} & \multicolumn{2}{|c|}{$6000 \mathrm{~Hz}$} & \multicolumn{2}{|c|}{$8000 \mathrm{~Hz}$} \\
\hline & $\mathrm{R}$ & $\mathrm{L}$ & $\mathrm{R}$ & $\mathrm{L}$ & $\mathrm{R}$ & $\mathrm{L}$ & $\mathrm{R}$ & $\mathrm{L}$ & $\mathrm{R}$ & $\mathrm{L}$ & $\mathrm{R}$ & $\mathrm{L}$ & $\mathrm{R}$ & $\mathrm{L}$ \\
\hline $\begin{array}{c}0-5 \\
\text { BC }\end{array}$ & 17 & 17 & 18 & 19 & 20 & 21 & 22 & 23 & 32 & 32 & & & & \\
\hline $\mathrm{AC}$ & 25 & 26 & 27 & 28 & 24 & 25 & 30 & 30 & 35 & 36 & 36 & 36 & 36 & 38 \\
\hline $\begin{array}{c}5-10 \\
\text { BC }\end{array}$ & 18 & 18 & 19 & 19 & 18 & 19 & 18 & 19 & 22 & 23 & & & & \\
\hline $\mathrm{AC}$ & 26 & 27 & 27 & 28 & 27 & 28 & 30 & 31 & 34 & 36 & 37 & 37 & 43 & 45 \\
\hline $\begin{array}{c}10-20 \\
B C\end{array}$ & 18 & 18 & 19 & 19 & 20 & 20 & 21 & 21 & 25 & 26 & & & & \\
\hline $\mathrm{AC}$ & 28 & 29 & 30 & 30 & 30 & 34 & 35 & 38 & 40 & 42 & 44 & 42 & 52 & 534 \\
\hline
\end{tabular}




\begin{tabular}{|c|c|c|c|c|c|c|c|c|c|c|c|c|c|c|}
\hline $\begin{array}{c}20-30 \\
\text { BC }\end{array}$ & 21 & 20 & 22 & 21 & 23 & 23 & 23 & 22 & 28 & 26 & & & & \\
\hline$A C$ & 31 & 31 & 32 & 32 & 33 & 32 & 37 & 36 & 44 & 44 & 49 & 49 & 49 & 49 \\
\hline
\end{tabular}

'P' Value $=<0.012$

Table 3:-Relationship between hearing thresholds and duration of Diabetes mellitus in different frequencies.

From the above Table -3 , it is clearly depicted that with increase in duration of diabetes mellitus the hearing thresholds in different frequencies are also increased in both Air conduction and Bone conduction modes. The results also shows that, with increase in duration of DM, the higher frequency regions are more affected when compared with the low frequency region. The statistical analysis also shows a high significant correlation between hearing thresholds and duration of diabetes mellitus. The results of the current study also support the previous findings of Zelenka and Kozak(1965), Tay HL et al (1995) and Stephen semen yikawe et al (2017).

\section{Conclusion:-}

The diabetic group have increased mean threshold at higher frequencies in comparison with non-diabetic group. Age and duration of diabetes showed a significant bilateral sensori neural high frequency hearing impairment with increased hearing thresholds. Hence it can be concluded that there is a direct relationship between diabetes and hearing impairment. Also the diabetes mellitus patients are advised to undergo periodic audiological evaluations and management.

\section{References:-}

1. Abdullahi Isa, BM Mubi, HI Grandawa, MB Sandabe, YB Ngamdu and AM Kodiya (2012), "Diabetes mellitus, Glycosylated haemoglobin levels and hearing impairment in adults", Sahel Medical Journal, Vol. 15. No. 1, January - March, 2012, $44-49$.

2. Ferrer JP, Biurrum O, Lorente J and Conget JI (1991), "Auditory function in young patients with type 1 Diabetes Mellitus”, Diabetes Research Clinical Practice, January, 11(1), 17 - 22.

3. Kutty S.R. et al (1998), “ Hearing Loss in Diabetes Mellitus", Indian Journal of Otology and Head and Neck Surgery, Vol. 4, $131-135$.

4. Heinemann, L-Muller. J, Kuhn.A and Lamprecht.A (1992), "Type 1 diabetes does not influence hearing abilities"., Journal of Audiological Medicine, 1, 20 - 29.

5. Huang Y.M. Pan C.Y. Rui G Cai X.H., Yu L.M. and Chou C.Y. (1990), "Study on the hearing impairment in diabetic patients", Chinese Journal of Otorhinolaryngology, 25, $354-356$.

6. Sheetal Krishnappa \& Khaja Naseeruddin (2014), "A Case study of age related hearing loss among diabetes patients", Indian Journal of Otology., Vol. 20, Issue - 4, 160 - 165.

7. Stephen semen yikawe, Kufre Robert Ishe, Anas ahmad Sabir, Josheph Hassan Solomon, Caleb Manya and Nasiru aliyu (2017), "Effect of duration of diabetes mellitus on hearing threshold among type 2 diabetics", Indian Journal of Otology, Vol. 23, Issue - 2, $113-116$. 